\title{
Improved Detection of Antibodies against SARS-CoV-2 by Microsphere-Based Antibody Assay
}

\author{
Carol Ho-Yan Fong ${ }^{1}$, Jian-Piao Cai ${ }^{1}{ }^{\mathbb{D}}$, Thrimendra Kaushika Dissanayake ${ }^{1}$, Lin-Lei Chen ${ }^{1}$, \\ Charlotte Yee-Ki Choi ${ }^{1}$, Lok-Hin Wong ${ }^{1}$, Anthony Chin-Ki Ng ${ }^{1}$, Polly K. P. Pang ${ }^{1}$, \\ Deborah Tip-Yin Ho ${ }^{1}$, Rosana Wing-Shan Poon ${ }^{2}$, Tom Wai-Hin Chung ${ }^{2}$, Siddharth Sridhar ${ }^{1}$ (D), \\ Kwok-Hung Chan ${ }^{1}{ }^{(\mathbb{D})}$, Jasper Fuk-Woo Chan ${ }^{1}$ (D), Ivan Fan-Ngai Hung ${ }^{3}$, Kwok-Yung Yuen ${ }^{1}$ and \\ Kelvin Kai-Wang To ${ }^{1, *}$ \\ 1 State Key Laboratory for Emerging Infectious Diseases, Carol Yu Centre for Infection, \\ Department of Microbiology, Li Ka Shing Faculty of Medicine, The University of Hong Kong, Pokfulam, \\ Hong Kong, China; chyfong@hku.hk (C.H.-Y.F.); caijuice@163.com (J.-P.C.); thrimendra@gmail.com (T.K.D.); \\ chenlinlei2346@gmail.com (L.-L.C.); yeekic@hku.hk (C.Y.-K.C.); wallacewongg@gmail.com (L.-H.W.); \\ anthonyng912@gmail.com (A.C.-K.N.); pollypang833@gmail.com (P.K.P.P.); tipyinho@hku.hk (D.T.-Y.H.); \\ sid8998@hku.hk (S.S.); chankh2@hku.hk (K.-H.C.); jfwchan@hku.hk (J.F.-W.C.); kyyuen@hku.hk (K.-Y.Y.) \\ 2 Department of Microbiology, Queen Mary Hospital, Hong Kong, China; \\ rosanapws@yahoo.com.hk (R.W.-S.P.); stwh.chung@gmail.com (T.W.-H.C.) \\ 3 Department of Medicine, Li Ka Shing Faculty of Medicine, The University of Hong Kong, Pokfulam, \\ Hong Kong, China; ivanhung@hku.hk \\ * Correspondence: kelvinto@hku.hk; Tel.: +852-2255-2413
}

Received: 14 August 2020; Accepted: 3 September 2020; Published: 9 September 2020

check for updates

\begin{abstract}
Currently available COVID-19 antibody tests using enzyme immunoassay (EIA) or immunochromatographic assay have variable sensitivity and specificity. Here, we developed and evaluated a novel microsphere-based antibody assay (MBA) for detecting immunoglobulin G (IgG) against severe acute respiratory syndrome coronavirus 2 (SARS-CoV-2) nucleoprotein (NP) and spike protein receptor binding domain (RBD). The seropositive cutoff value was set using a cohort of 294 anonymous serum specimens collected in 2018. The specificity was assessed using serum specimens collected from organ donors or influenza patients before 2020. Seropositive rate was determined among COVID-19 patients. Time-to-seropositivity and signal-to-cutoff $(\mathrm{S} / \mathrm{CO})$ ratio were compared between MBA and EIA. MBA had a specificity of 100\% (93/93; 95\% confidence interval (CI), 96-100\%) for anti-NP IgG, 98.9\% (92/93; 95\% CI 94.2-100\%) for anti-RBD IgG. The MBA seropositive rate for convalescent COVID-19 patients was 89.8\% (35/39) for anti-NP IgG and 79.5\% (31/39) for anti-RBD IgG. The time-to-seropositivity was shorter with MBA than EIA. MBA could better differentiate between COVID-19 patients and negative controls with higher S/CO ratio for COVID-19 patients, lower S/CO ratio with negative controls and fewer specimens in the equivocal range. MBA is robust, simple and is suitable for clinical microbiology laboratory for the accurate determination of anti-SARS-CoV-2 antibodies for diagnosis, serosurveillance, and vaccine trials.
\end{abstract}

Keywords: COVID-19; SARS-CoV-2; serology; flow cytometry; antibody assay

\section{Introduction}

In 2003, severe acute respiratory syndrome coronavirus (SARS-CoV) caused the first severe coronavirus epidemic, leading to more than 8000 cases, mainly in Asia [1,2]. In 2019, a novel coronavirus, now known as the severe acute respiratory syndrome coronavirus 2 (SARS-CoV-2), became the first coronavirus to cause a global pandemic [3]. Unlike the 2003 SARS-CoV, the novel 
SARS-CoV-2 transmits efficiently among humans, possibly due to high viral load at presentation [4] and efficient binding to the human receptor angiotensin receptor 2.

Antibody assays play a major role in clinical management, contact tracing, vaccine studies and the understanding of the epidemiology and pathogenesis of COVID-19 [5,6]. Antibody testing allows the retrospective diagnosis of an infection by comparing the antibody titer at the acute and at the convalescent phase of the illness. This is especially important for patients whose viral load is too low to be detected by virus detection assays. Furthermore, antibody testing is the preferred method for identifying subclinical infections. Several assays have been developed to detect antibodies against SARS-CoV-2. Enzyme immunoassay is a commonly used antibody assay for the detection of SARS-CoV-2 $[5,7,8]$. We have previously used enzyme immunoassay to determine the serial antibody profile of COVID-19 patients [9] and to determine the seroprevalence of SARS-CoV-2 in Hong Kong and in the Hubei province [5]. Lateral flow immunochromatographic assay allows for rapid detection, but currently available antibody testing assays for SARS-CoV-2 mainly rely on enzyme immunoassay or lateral flow immunochromatographic assays and the sensitivities of these assays are relatively low [10].

With the advance in technology, microsphere-based antibody assay (MBA) using flow cytometers have been developed for different clinical applications. The use of multiplex microsphere-based assays have been reported for respiratory viruses [11,12], viruses that cause childhood exanthems [13], and arthropod-borne viruses $[14,15]$. There are several advantages with MBA. First, since a large number of microspheres can be coated in a single reaction, the coating would be expected to be more uniformed than those of enzyme immunoassay (EIA), in which each well is coated separately. Second, the signal from MBA is detected inside a flow cytometer, which avoids potential external sources that may affect the measurement of the signal. For example, scratches on microtiter plates can affect the value for EIA. Third, MBA can be easily modified into a multiplex and high-throughput platform for simultaneous detection of different antigens in multiple specimens [12,16]. Finally, there are fewer steps and reagents involved for MBA than EIA (Supplementary Figure S1). In this study, we developed and evaluated an in-house MBA for the detection of immunoglobulin G (IgG) against SARS-CoV-2 nucleoprotein (NP) and spike protein receptor binding domain (RBD).

\section{Results}

\subsection{Establishing the $M B A$}

First, we determined the optimal microsphere-protein molar ratio for MBA. For NP, increasing the microsphere-protein molar ratio from 1:1 to 1:4 resulted in higher mean fluorescent intensity (MFI) values (Figure 1A). However, since a microsphere-protein molar ratio of 1:2 could already result in a high MFI value, this ratio was selected (Figure 1B). For RBD, there was no significant difference when increasing the microsphere-protein molar ratio from 1:1 to 1:4 (Figure 1C). Therefore, we have selected a microsphere-protein molar ratio of 1:1 for RBD (Figure 1D).

Next, we tested MBA at a ratio of 1:2 for NP and 1:1 for RBD with different negative controls and a positive control (Supplementary Figure S2). The negative controls include microspheres without biotinylated NP or RBD (green), diluent only control (orange), and a serum specimen collected in 2018 (blue). The positive control was a serum specimen from a COVID-19 patient (red). All three negative controls had an MFI of $<35$, while the serum specimen from the COVID-19 patient had an MFI of 1695 for anti-SARS-CoV-2 RBD IgG and 843 for anti-SARS-CoV-2 NP IgG. Next, we determined the optimal serum dilution for MBA and EIA using serially-diluted serum specimens from a COVID-19 patient. With both NP and RBD, the MFI plateaued at 1:400 for MBA and 1:100 provided the highest OD values with EIA (Figure 2). Hence, we have used 1:400 dilution for MBA and 1:100 for EIA for subsequent evaluation. 
A

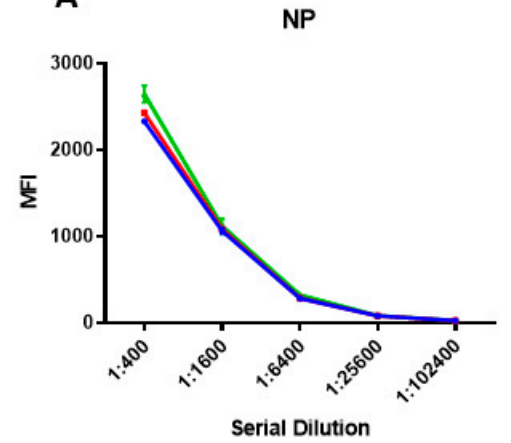

B

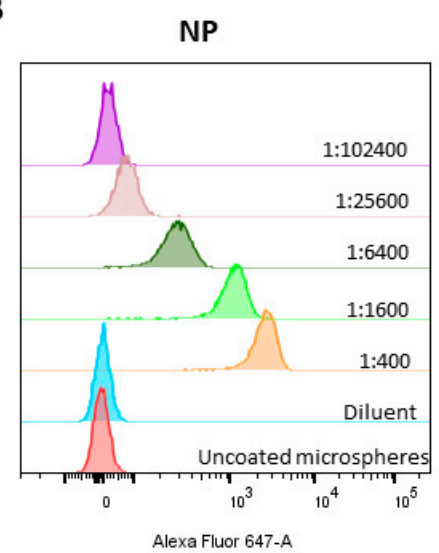

\section{C}
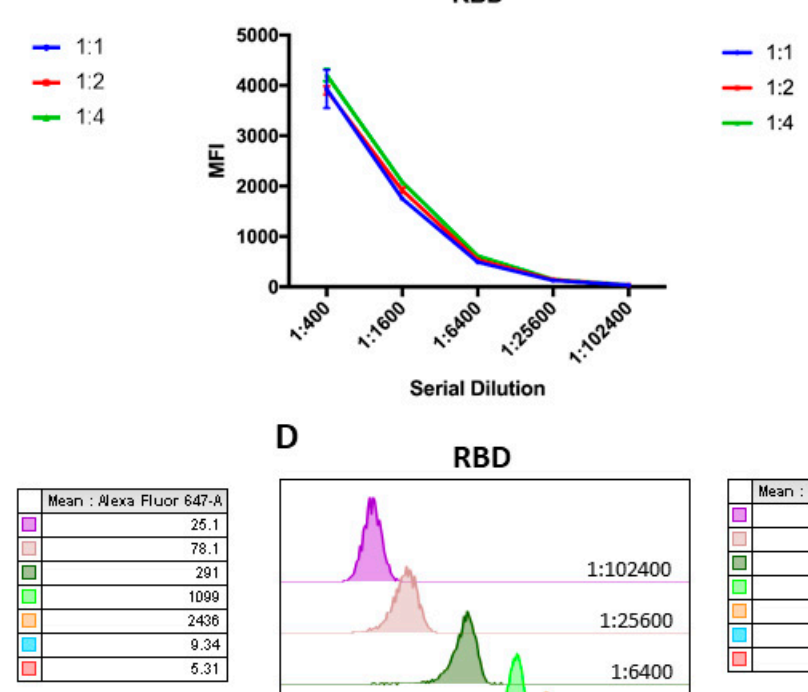

D
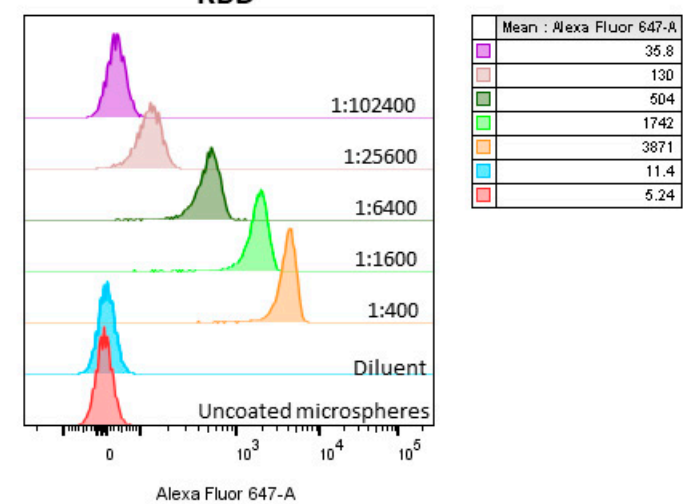

Figure 1. Determination of optimal microsphere-protein molar ratio for microsphere-based assay. Serum from a COVID-19 patient was used. The mean fluorescent intensity at different microsphere-protein molar ratio are shown for (A) nucleoprotein (NP) and (B) receptor binding domain (RBD), and the corresponding stacked histogram of selected microsphere-protein molar ratio are shown in (C) NP (1:2) and (D) RBD (1:1). Experiment was performed in triplicate with serum specimen collected from 3 different COVID-19 patients and a representative graph is shown. Error bar represents the standard error of mean from 3 replicates.

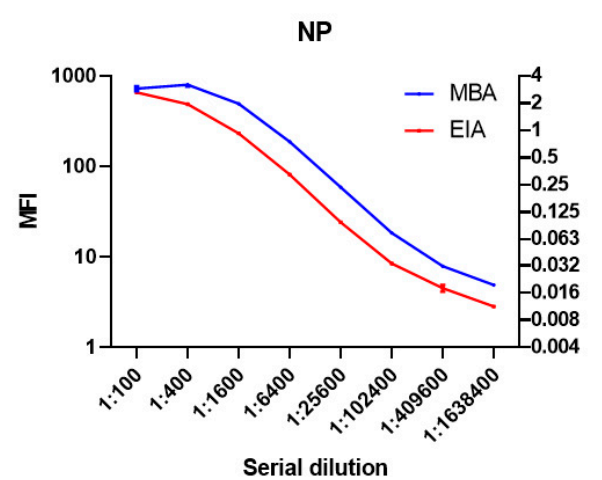

(A)

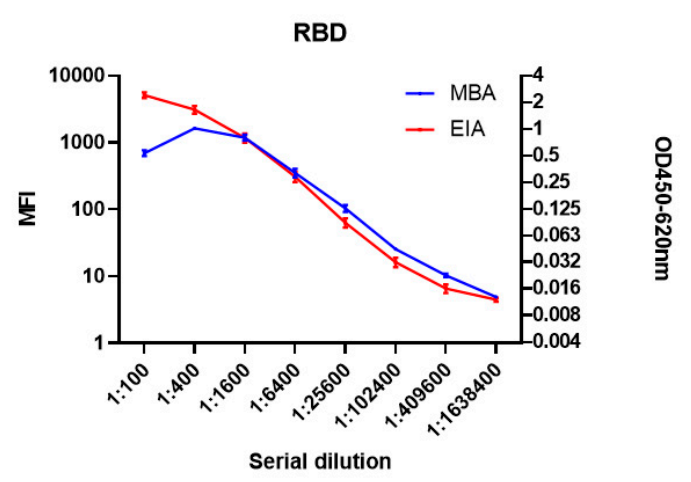

(B)

Figure 2. Dynamic range of microsphere-based antibody assay (MBA) and enzyme immunoassay (EIA) for (A) NP, and (B) RBD. Serial dilutions of COVID-19 serum were used to detect anti-NP IgG and anti-RBD IgG with MBA and EIA. Experiment was performed with $n=3$ and a representative graph is shown. Error bar represents the standard error of mean from 3 replicates.

To determine the seropositive cutoff value for MBA, microsphere-based NP and RBD IgG assay was performed on 294 anonymous archived serum specimens collected in 2018. These anonymous 
serum specimens encompass all age groups from the pediatric population to those aged over 80 years (Supplementary Table S1). We first excluded outliers with $>3$ SDs above the mean of the 294 archived anonymous serum specimens described previously [15]. After excluding the outliers (two for MBA anti-NP, one for MBA anti-RBD, four for EIA anti-NP, and four for EIA anti-RBD), the seropositive cutoff MFI (for MBA) or OD (for EIA) was then set as three SD above the mean of the remaining specimens. The seropositive cutoff values of MBA was 111.8 for anti-NP-IgG and 51.2 for anti-RBD IgG. The cutoff values of EIA was 0.58 for anti-NP-IgG and 0.54 for anti-RBD IgG.

To determine the specificity of the MBA, we retrieved 93 archived serum from organ donors collected between 2016 and $2018(n=53)$, and from patients with influenza virus infection between January and September $2019(n=40)$ (Figure 3). The specificity was 100\% (93/93; 95\% confidence interval (CI) 96-100\%) for anti-NP IgG and 98.9\% (92/93; 95\% CI 94.2-100\%) for anti-RBD IgG of all negative controls (organ donors and influenza patients). Subgroup analysis showed that for organ donors, the specificity was 100\% (53/53; 95\% CI: 93.3-100\%) for anti-NP and 98.1\% (52/53; 95\% CI, 89.9-100\%) for anti-RBD IgG; for influenza patients, the specificities of MBA anti-NP and anti-RBD IgG were both $100 \%$ (40/40; 95\% CI, 91.9-100\%).

A

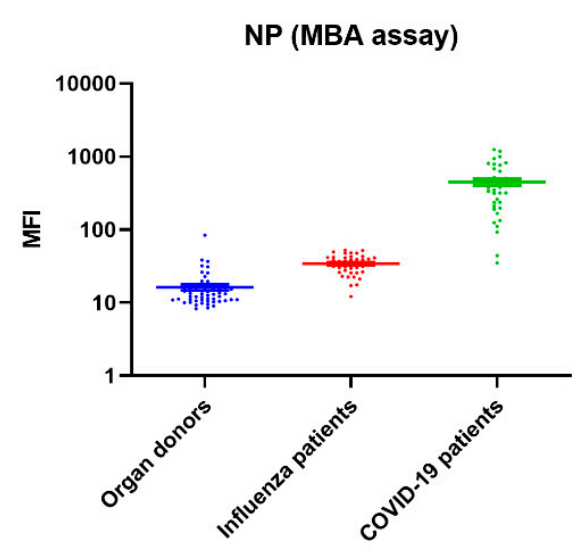

C

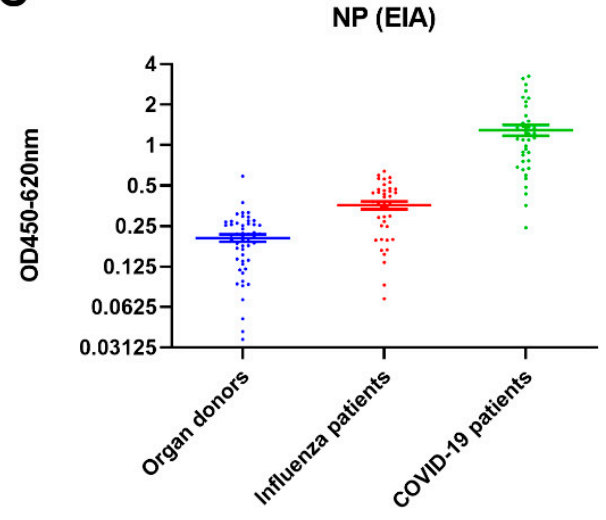

B

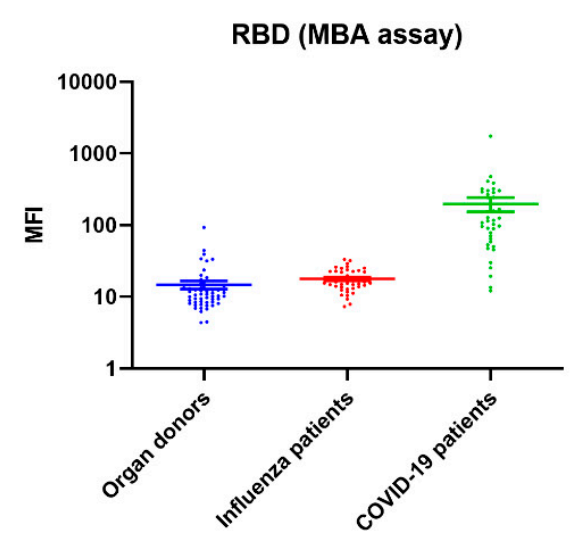

D

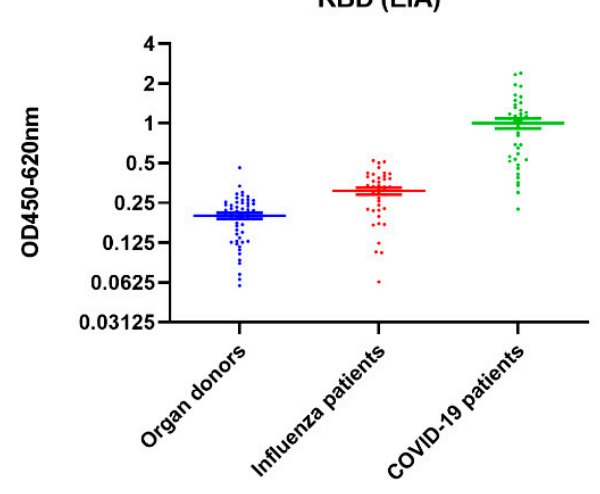

Figure 3. (A,B) Comparison of MFI between 39 COVID-19 patients, 40 influenza patients, and 53 organ donors for (A) NP and (B) RBD. (C,D) Comparison of OD values between COVID-19 patients, influenza patients, and organ donors for (C) NP and (D) RBD.

\subsection{Seropositive Rate and Time-To-Seropositivity}

Using the conditions optimized in the previous sections, we determined the seropositive rate of the 39 recovered COVID-19 patient using MBA, including 16 male and 23 female patients. The median 
age was 57 years (range 20 to 87 years old). Of the 39 patients, eight patients (20.5\%) had severe illness requiring oxygen supplementation. The blood specimens were collected at the out-patient follow-up clinic at a median of 44 days after symptom onset (interquatile range from 28 to 53 days). The seropositive rate was $89.8 \%$ (35/39) for anti-NP and 79.5\% (31/39) for anti-RBD IgG.

\subsection{Time-To-Seropositivity}

Next, we compared the time-to-seropositivity between MBA and EIA for 33 COVID-19 patients with serial samples available during hospitalization. Out of 33 patients, nine (27.3\%) patients had anti-NP IgG detected earlier by MBA, compared to one (3\%) detected earlier by EIA, and nine (27.3\%) patients had anti-RBD detected earlier by MBA, compared to four (12\%) by EIA. The time-to-seropositivity of MBA was shorter than that of EIA for both anti-NP (median time-to-seropositivity: 10 vs. 12 days; hazard ratio for time-to-seropositivity: $1.41 ; 95 \%$ confidence interval, $0.89-2.47, p=0.1546)$ and anti-RBD (median time-to-seropositivity: 13 vs. 14 days; hazard ratio for time-to-seropositivity: 1.05; 95\% CI, 0.62-1.79, $p=0.8655$ ), though not reaching statistical significance (Figure 4).
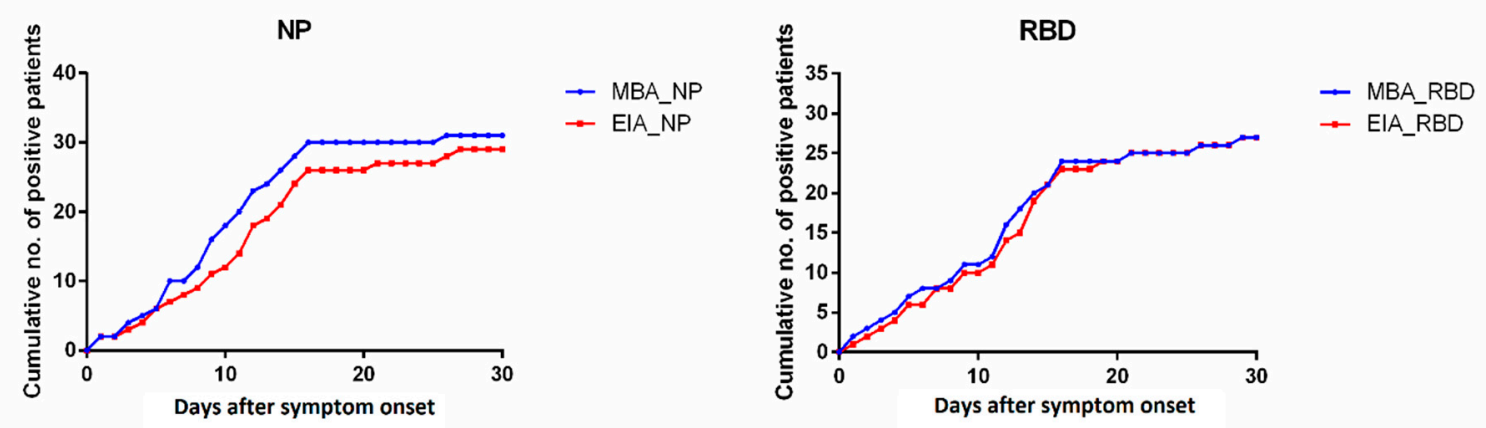

Figure 4. Cumulative count of seropositive COVID-19 patient specimens detected by MBA and EIA.

\subsection{Comparison of $\mathrm{S} / \mathrm{CO}$}

Next, we compared the signal-to-cutoff (S/CO) ratio (Figure 5). Among the convalescent serum specimens of the 39 COVID-19 patients, the S/CO ratio was significantly higher for MBA than that of EIA for both NP (median S/CO, 3.39 vs. 1.95; $p<0.0001$ ) and RBD (median S/CO, 2.23 vs. 1.92; $p=0.0001$ ). Among the 93 negative controls (organ donor and influenza patients), the S/CO ratio was significantly lower for MBA than that of EIA for both NP (median S/CO, 0.18 vs. 0.43; $p<0.0001$ ) and RBD (median S/CO, 0.25 vs. $0.43 ; p<0.0001$ ). There were fewer specimens that have signal values within the equivocal range (S/CO 0.9-1.1) for MBA than those in EIA (Table 1). In particular, there were significantly fewer within the equivocal range for MBA in the negative control group for anti-NP IgG $(0 \%(0 / 93)$ vs. $8.6 \%(8 / 93) ; p=0.0067)$.

Table 1. Comparison of S/CO Between MBA and EIA.

\begin{tabular}{|c|c|c|c|c|}
\hline \multirow[b]{2}{*}{ MBA } & \multicolumn{2}{|c|}{$\begin{array}{l}\text { Specimens Collected at Out-Patient Clinic } \\
\qquad(\mathrm{n}=39)\end{array}$} & \multicolumn{2}{|c|}{$\begin{array}{c}\text { Negative Controls } \\
\text { (Organ Donors + Influenza Patients) } \\
(\mathrm{n}-93)\end{array}$} \\
\hline & NP & RBD & NP & RBD \\
\hline $\mathrm{S} / \mathrm{CO}>1.1$ & $34(87.2 \%)$ & $29(74.4 \%)$ & 0 & $1(1.1 \%)$ \\
\hline S/CO 0-9-1.1 & $2(5.1 \%)$ & $5(12.8 \%)$ & 0 & $1(1.1 \%)$ \\
\hline $\mathrm{S} / \mathrm{CO}<0.9$ & $3(7.7 \%)$ & $5(12.8 \%)$ & 93 (100\%) & $91(97.8 \%)$ \\
\hline EIA & NP & RBD & NP & RBD \\
\hline $\mathrm{S} / \mathrm{CO}>1.1$ & $32(82.1 \%)$ & $26(66.7 \%)$ & 0 & 0 \\
\hline S/CO 0-9-1.1 & $3(7.7 \%)$ & $6(15.4 \%)$ & $8(8.6 \%)$ & $5(12.8 \%)$ \\
\hline $\mathrm{S} / \mathrm{CO}<0.9$ & $4(10.3 \%)$ & $7(18 \%)$ & $85(91.4 \%)$ & $88(94.6 \%)$ \\
\hline
\end{tabular}



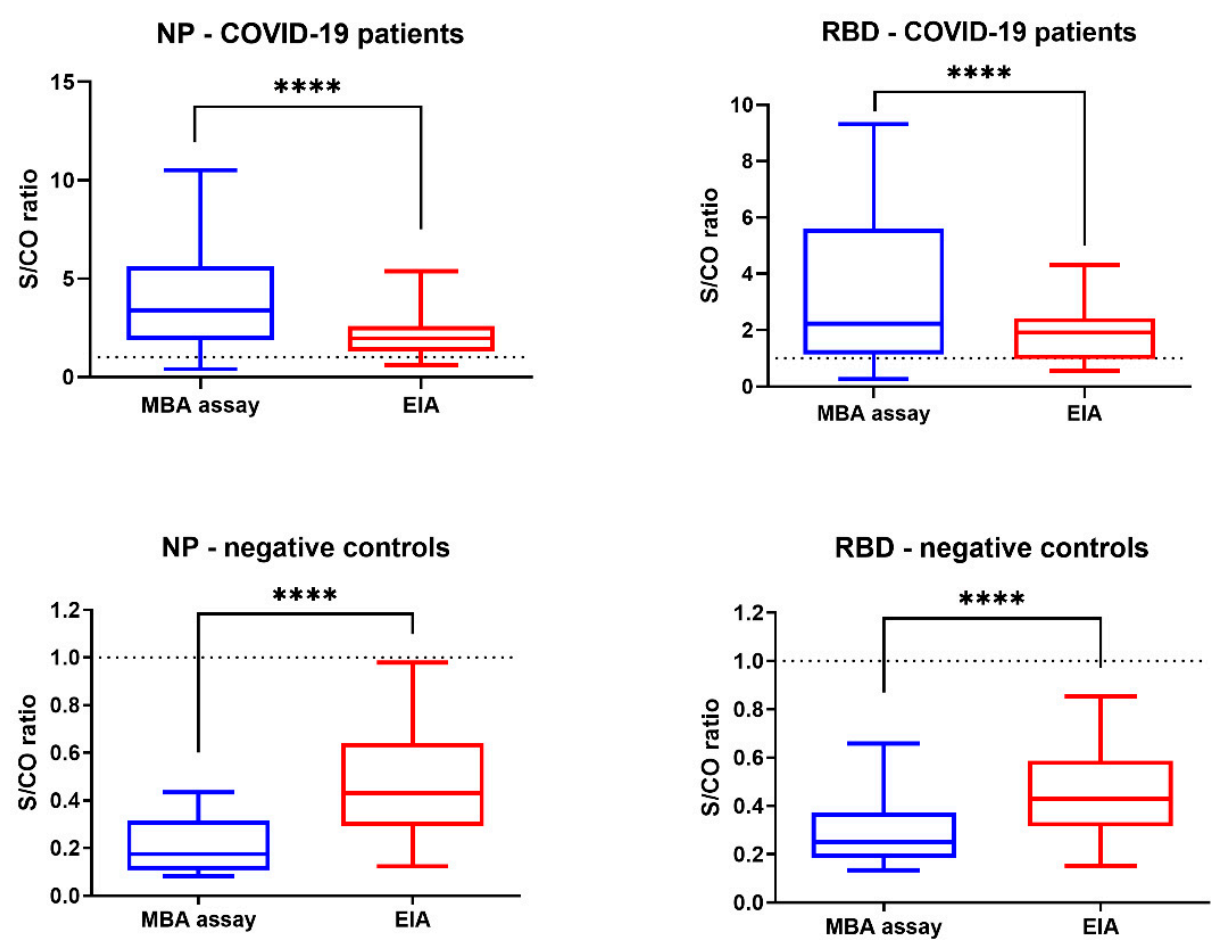

Figure 5. Comparison of signal-to-cutoff $(\mathrm{S} / \mathrm{CO})$ ratio between MBA and EIA for the serum specimens collected during the convalescent phase of 39 patients. ${ }^{* * *} p \leq 0.0001$.

\section{Discussion}

\subsection{Principle Outcomes}

This study evaluated our newly developed MBA in the detection of IgG against SARS-CoV-2 NP and spike protein RBD. MBA was found to be highly specific, and had a high seropositive rate for patients with COVID-19. The time of seropositivity was shorter for MBA than that of EIA. Furthermore, when compared with EIA, MBA had a significantly higher S/CO for COVID-19 patients and a significantly lower $\mathrm{S} / \mathrm{CO}$ for negative controls, and with fewer specimens within the equivocal range (S/CO 0.9-1.1). Hence, MBA is superior to EIA in the detection of IgG against SARS-CoV-2 antibody.

\subsection{Comparison with Other Studies}

In this study, we established the seropositive cutoff values using a pre-pandemic serum panel encompassing 294 individuals from all age groups, including young children $<10$ years old and elderly $>80$ years old. This is unlike other evaluations in which healthy young adult blood donors are used as negative controls [8]. In real life, patients often have comorbidities and many are elderlies [17]. For some studies, the specificity was evaluated using recombinant antigen instead of serum from non-COVID-19 patients [18].

Many rapid lateral flow immunochromatographic assays are now commercially available. Although these immunochromatographic assays are convenient for testing, the results of these assays are poor $[19,20]$ or with variable sensitivity and specificity [21]. Our flow-cytometry-based microsphere-based antibody assay has several advantages over immunochromatographic assays. First, MBA can provide a quantitative result, while immunochromatographic assay can only give qualitative results. Therefore, MBA can assess the rise of antibody levels in a quantitative manner. Second, the interpretation of immunochromatographic assays can be difficult if the band is weakly positive. Hence, there may be inter-operator differences in interpreting the results. In contrast, MBA can provide an objective readout, eliminating inter-operator differences in result interpretations. 
Virus neutralization assay can detect antibodies that prevent viruses from infecting cells. Since neutralization assays require the use of live SARS-CoV-2 virus, they can only be performed in biosafety level 3 laboratories. Hence, neutralization assays cannot be performed in most clinical laboratories. In contrast, the detection of IgG with recombinant virus antigens can be performed safely in biosafety level 2 clinical microbiology laboratories. Previous studies have shown that IgG correlates well with neutralizing antibody titer $[8,22]$.

A recent study measures anti-SARS-CoV-2 IgG level using a magnetic bead-based assay [18]. However, since a magnetic chemiluminescence analyzer is required, this may not be feasible in most clinical laboratories. In this study, our in-house MBA only requires a simple flow cytometer that is available in most clinical laboratories. Our technique can be easily applied to any laboratory with a standard flow cytometer. After simple gating and optimization, no further adjustments are required. Our method can be easily extended to other protein antigens.

\subsection{Limitations of This Study}

First, we only recruited adult patients. Further evaluation should be performed in pediatric patients. Second, as for all serology assays, cross-reactivity may affect the results [8]. Even for the pre-pandemic serum, some samples can be seropositive for SARS-CoV-2 because of cross reaction with other human coronaviruses, especially from lineage B betacoronavirus. Third, samples were not tested for virus neutralization and therefore neutralizing activities of the detected $\operatorname{Ig} G$ antibodies are unknown.

\subsection{Conclusions and Implications for Clinical Practice and Research Studies}

In this study, we have demonstrated that our novel flow-cytometry-based MBA allowed for an earlier detection of anti-SARS-CoV-2 antibodies among COVID-19 patients than EIA. MBA also had fewer equivocal results than EIA. A rapid and accurate diagnosis of the SARS-CoV-2 is crucial for clinicians to provide appropriate treatment to patients, to limit further spread of the virus and, ultimately, to eliminate another peak of pandemic risk to the public. Furthermore, our assay can be used to investigate the immune response in COVID-19 patients, establishing retrospective diagnosis especially for patients with immune-mediated diseases, determining seroprevalence in epidemiological studies, and assessing the efficacy of novel vaccines.

\section{Materials and Methods}

\subsection{Serum Specimens}

To set the cutoff for the EIA and MBA, we retrieved 294 archived anonymous serum specimens from the clinical biochemistry laboratory collected between April and June 2018, which were used in our previous study [23]. For assessment of specificity, we retrieved 93 sera collected before 2020, including 53 sera collected from potential organ donors between 2016 and 2018 in a study on hepatitis $\mathrm{E}$ in HKSAR, and from 40 influenza patients between January and September 2019. For COVID-19 patients, serum specimens were collected from 39 recovered COVID-19 patients during the convalescent phase at the infectious disease out-patient follow-up clinic at Queen Mary Hospital. To assess the time-to-seropositivity, we retrieved 161 serial serum specimens obtained from 33 of these 39 patients during hospitalization. This study has been approved by the HKU/HA HKW Institutional Review Board (UW 13-265 and UW 18-141). Written informed consent was obtained from all COVID-19 patients.

\subsection{Cloning, Purification and Biotinylation of Recombinant NP and Spike Protein RBD of SARS-CoV-2}

Cloning and purification of SARS-CoV-2 NP and spike RBD were performed as we described previously [9]. The purified NP and spike protein RBD were biotinylated with EZ-link ${ }^{\mathrm{TM}}$ Sulfo-NHS-Biotin (ThermoFisher Scientific, Waltham, MA, USA). Please refer to Supplementary Methods for details. 


\subsection{Enzyme Immunoassay for NP and Spike RBD}

EIA for NP and RBD was performed as we described previously [9] (See Supplementary Methods for details).

\subsection{Microsphere-Based Antibody Assay}

$1.43 \times 10^{7}$ of $4.95 \mu \mathrm{M}$ SuperAvidin ${ }^{\mathrm{TM}}$ coated microspheres (Bangs Laboratories, Fishers, Indiana, USA) were washed with $500 \mu \mathrm{L}$ of phosphate buffered saline (PBS) and $1 \%$ bovine serum albumin (BSA), and were centrifuged at $14,000 \mathrm{rpm}$ at $4{ }^{\circ} \mathrm{C}$ for $15 \mathrm{~min}$. The washing was discarded and microspheres were resuspended in $1 \mathrm{~mL}$ of $1 \%$ BSA, followed by sonication for 30 s. For every $1.43 \times 10^{7}$ microspheres, microspheres were coated with different molar ratio of biotinylated NP, 1:1 (2.3 $\mu \mathrm{g}), 1: 2(4.6 \mu \mathrm{g}), 1: 4(9.2 \mu \mathrm{g})$ or biotinylated spike RBD, 1:1 (1.2 $\mu \mathrm{g}), 1: 2(2.4 \mu \mathrm{g}), 1: 4(4.8 \mu \mathrm{g})$, and were incubated at $4{ }^{\circ} \mathrm{C}$ with shaking. After overnight incubation, $2.86 \times 10^{5}$ microspheres were distributed to each well of V-bottom 96 well plates and centrifuged at $1500 \mathrm{rpm}, 4^{\circ} \mathrm{C}$ for 5 min to remove the uncoated protein. The supernatant was discarded and microspheres were blocked with $30 \mu \mathrm{L}$ of fetal bovine serum (FBS) for $1 \mathrm{~h}$ at room temperature with shaking. After blocking, FBS were removed by centrifugation at $1500 \mathrm{rpm}$ and $4{ }^{\circ} \mathrm{C}$ for $5 \mathrm{~min}$, then $30 \mu \mathrm{L}$ of serum or diluent $(1 \%$ BSA, PBS) was added to each well. Samples were incubated at room temperature with shaking. After 2-h incubation, beads were washed by adding $100 \mu \mathrm{L}$ of PBS and $1 \%$ BSA, centrifuged at $1500 \mathrm{rpm}, 4^{\circ} \mathrm{C}$ for $5 \mathrm{~min}$. Supernatant was discarded, $30 \mu \mathrm{L}, 5 \mu \mathrm{g} / \mathrm{mL}$ of Alexa Fluor ${ }^{\circledR} 647$ AffinPure Fab fragment goat anti-human IgG, Fc $\gamma$ fragment specific (Jackson ImmunoResearch, West Grove, Pennsylvania, USA) in PBS and 1\% BSA was added to each well and incubated at room temperature in the dark with shaking. After 1-h incubation, beads were washed by adding $100 \mu \mathrm{L}$ of PBS and 1\% BSA, centrifuged at $1500 \mathrm{rpm}, 4{ }^{\circ} \mathrm{C}$ for $5 \mathrm{~min}$. Supernatant was discarded and microspheres were resuspended with $200 \mu \mathrm{L}$ PBS and 1\% BSA. Flow cytometry analysis was performed using BD LSR Fortessa analyzer (BD Biosciences, San Jose, CA, USA), and the flow cytometry data were analyzed using FlowJo v10.6.2 (FlowJo LLC, Ashland, OR, USA) (Supplementary Figure S3).

\subsection{Statistical Analysis}

Statistical analysis was performed using PRISM 6.0. We compared categorical variables using Fisher's exact test and continuous variables using Mann-Whitney $U$ test. The S/CO ratio was compared between MBA and EIA by Wilcoxon matched-pairs signed rank test. A $p$ value of less than 0.05 was judged statistically significant.

Supplementary Materials: Supplementary Materials can be found at http://www.mdpi.com/1422-0067/21/18/ 6595/s1.

Author Contributions: Conceptualization, C.H.-Y.F. and K.K.-W.T.; data curation, C.H.-Y.F. and L.-L.C.; formal analysis, C.H.-Y.F. and K.K.-W.T.; funding acquisition, K.K.-W.T.; investigation, K.K.-W.T.; methodology, C.H.-Y.F., J.-P.C., T.K.D. and L.-L.C.; project administration, K.K.-W.T.; Resources, J.-P.C., C.Y.-K.C., L.-H.W., A.C.-K.N., P.K.P.P., D.T.-Y.H., S.S., K.-H.C., I.F.-N.H., K.-Y.Y. and K.K.-W.T.; supervision, K.K.-W.T.; validation, C.H.-Y.F. and K.K.-W.T; writing-original draft, C.H.-Y.F. and K.K.-W.T; writing-review and editing, C.H.-Y.F., J.-P.C., T.K.D., L.-L.C., C.Y.-K.C., L.-H.W., A.C.-K.N., P.K.P.P., D.T.-Y.H., R.W.-S.P., T.W.-H.C., S.S., K.-H.C., J.F.-W.C., I.F.-N.H., K.-Y.Y. and K.K.-W.T. All authors have read and agreed to the published version of the manuscript.

Funding: This study was supported by the Public Sector Trial Scheme for the Prevention and Control of Coronavirus Disease 2019 (COVID-19) in Hong Kong (SST/115/20GP), and donations of Richard Yu and Carol Yu, May Tam Mak Mei Yin, the Shaw Foundation Hong Kong, Michael Seak-Kan Tong, Respiratory Viral Research Foundation Limited, Hui Ming, Hui Hoy and Chow Sin Lan Charity Fund Limited, Chan Yin Chuen Memorial Charitable Foundation, Marina Man-Wai Lee, the Jessie \& George Ho Charitable Foundation, Perfect Shape Medical Limited, and Kai Chong Tong; The funding sources had no role in the study design, data collection, analysis, interpretation, or writing of the report.

Conflicts of Interest: The authors declare no conflict of interest. 


\section{Abbreviations}

$\begin{array}{ll}\text { MBA } & \text { Microsphere-based antibody assay } \\ \text { EIA } & \text { Enzyme immunoassay } \\ \text { SARS-CoV } & \text { Severe acute respiratory syndrome coronavirus } \\ \text { SARS-CoV-2 } & \text { Severe acute respiratory syndrome coronavirus 2 } \\ \text { NP } & \text { SARS-CoV-2 nucleoprotein } \\ \text { RBD } & \text { Spike protein receptor binding domain } \\ \text { IgG } & \text { Immunoglobulin G } \\ \text { FBS } & \text { Fetal bovine serum } \\ \text { PBS } & \text { Phosphate-buffered saline } \\ \text { S/CO } & \text { Signal-to-cutoff } \\ \text { CI } & \text { Confidence interval } \\ \text { MFI } & \text { Mean fluorescent intensity }\end{array}$

\section{References}

1. Peiris, J.S.M.; Lai, S.T.; Poon, L.L.M.; Guan, Y.; Yam, L.Y.C.; Lim, W.; Nicholls, J.; Yee, W.K.S.; Yan, W.W.; Cheung, M.T.; et al. Coronavirus as a possible cause of severe acute respiratory syndrome. Lancet 2003, 361, 1319-1325. [CrossRef]

2. Cheng, V.C.; Lau, S.K.; Woo, P.C.; Yuen, K.Y. Severe acute respiratory syndrome coronavirus as an agent of emerging and reemerging infection. Clin. Microbiol. Rev. 2007, 20, 660-694. [CrossRef]

3. Chan, J.F.; Yuan, S.; Kok, K.H.; To, K.K.; Chu, H.; Yang, J.; Xing, F.; Liu, J.; Yip, C.C.; Poon, R.W.; et al. A familial cluster of pneumonia associated with the 2019 novel coronavirus indicating person-to-person transmission: A study of a family cluster. Lancet 2020, 395, 514-523. [CrossRef]

4. To, K.K.; Tsang, O.T.; Chik-Yan Yip, C.; Chan, K.H.; Wu, T.C.; Chan, J.M.C.; Leung, W.S.; Chik, T.S.; Choi, C.Y.; Kandamby, D.H.; et al. Consistent detection of 2019 novel coronavirus in saliva. Clin. Infect. Dis. 2020. [CrossRef]

5. To, K.K.-W.; Cheng, V.C.-C.; Cai, J.; Chan, K.; Chen, L.; Wong, L.; Choi, C.Y.; Fong, C.H.; Ng, A.C.; Lu, L.; et al. Seroprevalence of SARS-CoV-2 in Hong Kong Special Administrative Region and our returnees evacuated from Hubei province of China: A multi-cohort study. Lancet Microbe 2020, 1, e111-e118. [CrossRef]

6. Petherick, A. Developing antibody tests for SARS-CoV-2. Lancet 2020, 395, 1101-1102. [CrossRef]

7. Zhao, J.; Yuan, Q.; Wang, H.; Liu, W.; Liao, X.; Su, Y.; Wang, X.; Yuan, J.; Li, T.; Li, J.; et al. Antibody responses to SARS-CoV-2 in patients of novel coronavirus disease 2019. Clin. Infect. Dis. 2020. [CrossRef]

8. Okba, N.M.A.; Muller, M.A.; Li, W.; Wang, C.; GeurtsvanKessel, C.H.; Corman, V.M.; Lamers, M.M.; Sikkema, R.S.; de Bruin, E.; Chandler, F.D.; et al. Severe Acute Respiratory Syndrome Coronavirus 2-Specific Antibody Responses in Coronavirus Disease 2019 Patients. Emerg. Infect. Dis. 2020, 26, 1478-1488. [CrossRef]

9. To, K.K.; Tsang, O.T.; Leung, W.S.; Tam, A.R.; Wu, T.C.; Lung, D.C.; Yip, C.C.; Cai, J.P.; Chan, J.M.; Chik, T.S.; et al. Temporal profiles of viral load in posterior oropharyngeal saliva samples and serum antibody responses during infection by SARS-CoV-2: An observational cohort study. Lancet. Infectious Diseases 2020, 20, 565-574. [CrossRef]

10. Montesinos, I.; Gruson, D.; Kabamba, B.; Dahma, H.; Van den Wijngaert, S.; Reza, S.; Carbone, V.; Vandenberg, O.; Gulbis, B.; Wolff, F.; et al. Evaluation of two automated and three rapid lateral flow immunoassays for the detection of anti-SARS-CoV-2 antibodies. J. Clin. Virol. 2020, 128, 104413. [CrossRef]

11. Zhang, Y.; Brooks, W.A.; Goswami, D.; Rahman, M.; Luby, S.P.; Erdman, D.D. A duplex recombinant viral nucleoprotein microbead immunoassay for simultaneous detection of seroresponses to human respiratory syncytial virus and metapneumovirus infections. J. Virol. Methods 2014, 206, 55-62. [CrossRef]

12. Trivedi, S.U.; Miao, C.; Sanchez, J.E.; Caidi, H.; Tamin, A.; Haynes, L.; Thornburg, N.J. Development and Evaluation of a Multiplexed Immunoassay for Simultaneous Detection of Serum IgG Antibodies to Six Human Coronaviruses. Sci. Rep. 2019, 9, 1390. [CrossRef]

13. Smits, G.P.; van Gageldonk, P.G.; Schouls, L.M.; van der Klis, F.R.; Berbers, G.A. Development of a bead-based multiplex immunoassay for simultaneous quantitative detection of IgG serum antibodies against measles, mumps, rubella, and varicella-zoster virus. Clin. Vaccine Immunol. 2012, 19, 396-400. [CrossRef] 
14. Basile, A.J.; Horiuchi, K.; Panella, A.J.; Laven, J.; Kosoy, O.; Lanciotti, R.S.; Venkateswaran, N.; Biggerstaff, B.J. Multiplex microsphere immunoassays for the detection of IgM and IgG to arboviral diseases. PLoS ONE 2013, 8, e75670. [CrossRef]

15. Rogier, E.W.; Moss, D.M.; Mace, K.E.; Chang, M.; Jean, S.E.; Bullard, S.M.; Lammie, P.J.; Lemoine, J.F.; Udhayakumar, V. Use of Bead-Based Serologic Assay to Evaluate Chikungunya Virus Epidemic, Haiti. Emerg. Infect. Dis. 2018, 24, 995-1001. [CrossRef]

16. Kranz, L.M.; Gartner, B.; Michel, A.; Pawlita, M.; Waterboer, T.; Brenner, N. Development and validation of HIV-1 Multiplex Serology. J. Immunol. Methods 2019, 466, 47-51. [CrossRef]

17. Guan, W.J.; Ni, Z.Y.; Hu, Y.; Liang, W.H.; Ou, C.Q.; He, J.X.; Liu, L.; Shan, H.; Lei, C.L.; Hui, D.S.C.; et al. Clinical Characteristics of Coronavirus Disease 2019 in China. N. Engl. J. Med. 2020, 382, 1708-1720. [CrossRef]

18. Long, Q.X.; Liu, B.Z.; Deng, H.J.; Wu, G.C.; Deng, K.; Chen, Y.K.; Liao, P.; Qiu, J.F.; Lin, Y.; Cai, X.F.; et al. Antibody responses to SARS-CoV-2 in patients with COVID-19. Nat. Med. 2020, 26, 845-848. [CrossRef]

19. Imai, K.; Takiko, T.; Ikeda, M.; Noguchi, S.; Kitagawa, Y.; Matuoka, M.; Miyoshi, K.; Tarumoto, N.; Sakai, J.; Ito, T.; et al. Clinical evaluation of an immunochromatographic $\operatorname{IgM} / \operatorname{IgG}$ antibody assay and chest computed tomography for the diagnosis of COVID-19. J. Clin. Virol. 2020, 128, 104393. [CrossRef]

20. Abbasi, J. The Promise and Peril of Antibody Testing for COVID-19. JAMA 2020, 323, 1881-1883. [CrossRef]

21. Demey, B.; Daher, N.; François, C.; Lanoix, J.P.; Duverlie, G.; Castelain, S.; Brochot, E. Dynamic profile for the detection of anti-SARS-CoV-2 antibodies using four immunochromatographic assays. J. Infect. 2020, 81, e6-e10. [CrossRef]

22. Perera, R.A.; Mok, C.K.; Tsang, O.T.; Lv, H.; Ko, R.L.; Wu, N.C.; Yuan, M.; Leung, W.S.; Chan, J.M.; Chik, T.S.; et al. Serological assays for severe acute respiratory syndrome coronavirus 2 (SARS-CoV-2), March 2020. Euro Surveill. Bull. Eur. Mal. Trans. Eur. Commun. Dis. Bull. 2020, 25, 2000421. [CrossRef]

23. Chen, L.L.; Wu, W.L.; Chan, W.M.; Fong, C.H.Y.; Ng, A.C.K.; Ip, J.D.; Lu, L.; Dissanayake, T.K.; Ding, X.; Cai, J.P.; et al. Assessment of population susceptibility to upcoming seasonal influenza epidemic strain using interepidemic emerging influenza virus strains. Epidemiol. Infect. 2019, 147, e279. [CrossRef] [PubMed]

(C) 2020 by the authors. Licensee MDPI, Basel, Switzerland. This article is an open access article distributed under the terms and conditions of the Creative Commons Attribution (CC BY) license (http://creativecommons.org/licenses/by/4.0/). 